\title{
TENDÊNCIAS E PERSPECTIVAS DA ADMINISTRAÇÃO EM ENFERMAGEM: UM ESTUDO NA SANTA CASA DE BELO HORIZONTE-MG ${ }^{1}$
}

Carla Aparecida Spagnol ${ }^{2}$

Clarice Aparecida Ferraz ${ }^{3}$

Spagnol CA, Ferraz CA. Tendências e perspectivas da administração em enfermagem: um estudo na Santa Casa de Belo Horizonte-MG. Rev Latino-am Enfermagem 2002 janeiro-fevereiro; 10(1):15-20.

A Santa Casa de Belo Horizonte implantou um novo Sistema de Gestão que a caracterizou como uma organização flexível. Partindo desse contexto, delineamos como objetivos deste estudo: analisar a forma da administração em enfermagem, considerando a implantação do SIGESC; descrever como a equipe de enfermagem percebe a comunicação, o processo decisório e as relações interpessoais; identificar possivveis tendências e perspectivas presentes na prática administrativa desenvolvida. Evidenciamos um momento de transição da administração em enfermagem que apresenta traços da gerência clássica e da gerência contemporânea. Entretanto, sinalizamos tendências e perspectivas que poderão contribuir para a reorganização do processo de trabalho da enfermagem na área hospitalar.

DESCRITORES: enfermagem, administração hospitalar, hospitais

\section{TRENDS AND PERSPECTIVES OF NURSING ADMINISTRATION: A STUDY IN THE "SANTA CASA" HOSPITAL OF BELO HORIZONTE-MG, BRAZIL}

The "Santa Casa" Hospital of Belo Horizonte has implemented a new management system that has characterized it as a flexible organization. Based on this context, the authors of this research defined the following objectives: to analyze nursing administration by considering the implementation of the Management System (SIGESC), to describe how the nursing team perceives communication, the decision-making process and interpersonal relationships, to identify possible trends and perspectives present in the administrative practice developed. A time of transition in nursing administration that presents characteristics of classical management and contemporaneous management was shown as well as trends and perspectives that will contribute to the reorganization of nursing work in hospitals.

KEY WORDS: nursing, hospital administration, hospitals

\section{TENDENCIAS Y PERSPECTIVAS DE LA ADMINISTRACIÓN EN ENFERMERÍA UN ESTUDIO EN LA SANTA CASA DE BELO HORIZONTE-MG}

La Santa Casa de Belo Horizonte, implantó un nuevo Sistema de Gestión, caracterizándose como una organización flexible. Partiendo de este contexto, delimitamos como objetivos: analizar la forma de administración en enfermería, considerando la implementación del SIGESC; describir como el equipo de enfermería percibe la comunicación, el proceso de toma de decisiones y las relaciones interpersonales; identificar posibles tendencias y perspectivas presentes en la práctica administrativa desarrollada. Evidenciamos un momento de transición de la administración en enfermería que presenta trazos de la gerencia clásica y de la gerencia contemporánea. Por ahora, señalamos tendencias y perspectivas que podrán contribuir para la reorganización del proceso de trabajo de enfermería en el área hospitalaria.

DESCRIPTORES: enfermería, administración hospitalaria, hospitales

\footnotetext{
${ }^{1}$ Este artigo é uma síntese da dissertação de Mestrado intitulada: "Tendências e perspectivas da administração em enfermagem: um estudo na Santa Casa de Belo Horizonte-MG", defendida em 19 de outubro de 2000 na Escola de Enfermagem de Ribeirão Preto da Universidade de São Paulo, Centro Colaborador da OMS para o desenvolvimento da pesquisa em enfermagem; ${ }^{2}$ Mestre em Enfermagem, Professor Assistente da Escola de Enfermagem da Universidade Federal de Minas Gerais, e-mail: spagnol@enf.ufmg.br; ${ }^{3}$ Professor Doutor da Escola de Enfermagem de Ribeirão Preto da Universidade de São Paulo, Centro Colaborador da OMS para o desenvolvimento da pesquisa em enfermagem, Orientadora da Dissertação
} 


\section{APRESENTANDO 0 ESTUDO REALIZADO}

objeto de estudo desta investigação delimita-se na identificação e análise da forma de administração em enfermagem desenvolvida na Santa Casa de Belo Horizonte-MG, tendo em vista a reestruturação administrativa que ocorreu, neste hospital, a partir de 1996.

Até 1995, a Santa Casa, apresentava uma estrutura organizacional rígida, representada por um organograma baseado na lógica da departamentalização, segundo os grupos profissionais existentes e com a presença de vários níveis hierárquicos. 0 Departamento de Enfermagem era o órgão responsável por todas as questões relacionadas à assistência de enfermagem e à profissão, sendo que a Coordenadora Geral gerenciava todas as atividades técnicas e administrativas da enfermagem desenvolvidas no hospital.

0 processo decisório estava centralizado no topo da hierarquia, fazendo com que grande parte das decisões fosse incoerente com a realidade dos setores de trabalho. Além disso, percebíamos um certo autoritarismo na tomada de decisões.

A estrutura do Departamento de Enfermagem evidenciava ainda uma comunicação verticalizada e extremamente formal, que se processava de forma descendente, ou seja, as ordens partiam da alta direção para os funcionários da base. No sentido ascendente, as informações relevantes ao processo decisório, muitas vezes se perdiam ou eram distorcidas. Era notória uma obstrução no fluxo da comunicação, ocasionando a demora na tomada de decisão e distorções nas informações.

Aliado a essas questões, administração de enfermagem voltava-se, basicamente, para o controle das tarefas e era realizado pelas enfermeiras assistenciais e supervisoras. Estas últimas ocupavam cargos de chefia intermediária envolvendo-se pouco com os problemas da equipe sendo, a maioria, encaminhada à Coordenadora Geral do serviço. A lógica do controle é uma característica marcante da Gerência Clássica, que centraliza as ações do gerente na supervisão e controle das atividades desenvolvidas ${ }^{(1)}$.

Apesar das contribuições que o modelo clássico de gerência trouxe para a organização do trabalho na área hospitalar, a nossa experiência profissional, associada ao conhecimento da literatura consultada, mostrou-nos que a estrutura organizacional do Departamento de Enfermagem da Santa Casa e o estilo clássico de gestão desenvolvido produziam efeitos negativos que prejudicavam a agilidade e a operacionalização do processo de trabalho.

Estudiosos da área da administração alertam que nos últimos anos o modelo clássico de gestão não tem respondido adequadamente às necessidades das empresas do futuro ${ }^{(2-3)}$. Isto porque estamos vivendo num mundo de instabilidades e incertezas decorrentes, principalmente, da velocidade das transformações que ocorrem nos setores: político, social, econômico e cultural, destacando aqui o crescimento acelerado das novas tecnologias. Neste sentido, as organizações, de um modo geral, estão buscando novas concepções gerenciais a fim de se tornarem mais leves e ágeis, respondendo, rapidamente, às necessidades dos seus clientes e trabalhadores.

Atualmente, os hospitais, vêm atravessando diversas crises financeiras e administrativas além de conviverem com a diversidade tecnológica nos últimos anos. Destacamos o caso das Santas Casas de Misericórdia, que são entidades filantrópicas e, na maioria das vezes, dependentes do SUS (Sistema Único de Saúde) ou de doações para cobrirem suas despesas.

Para garantir a sobrevivência, alguns hospitais filantrópicos, estão buscando novas concepções gerenciais, que visam agilizar os processos de trabalho, otimizar recursos e qualificar os serviços. Não fugindo a este contexto e optando por sobreviver frente à nova ordem social e econômica, a Santa Casa de Belo Horizonte-MG criou, em 1996, o novo Sistema de Gestão da Santa Casa (SIGESC).

Após a implantação do SIGESC, houve "um verdadeiro desmonte da antiga lógica administrativa pautada nos princípios da administração clássica", sendo que este novo modelo de gestão apresenta características de horizontalização das relações; redução dos níveis hierárquicos; descentralização do poder decisório e incremento do processo de comunicação. Essas características são consideradas facilitadoras do trabalho desenvolvido ${ }^{(4)}$.

Perante a reconfiguração estrutural e gerencial que vem ocorrendo na Santa Casa, acreditamos que de alguma forma a administração em enfermagem está incorporando mudanças no seu estilo tradicional. Assim, nossas reflexões foram transformadas na seguinte questão: diante das mudanças organizacionais que estão ocorrendo na Santa Casa de Belo Horizonte-MG, como a administração em enfermagem está se configurando no trabalho cotidiano?

A revisão de literatura mostrou que são poucos os estudos que têm analisado a prática cotidiana da administração em enfermagem em contextos de mudanças nas organizações hospitalares. Portanto, os resultados deste estudo poderão contribuir para a identificação de novas práticas instituídas e assim indicar aspectos relevantes para a (re) construção da gerência em enfermagem.

Diante destas considerações e justificativas delineamos os seguintes objetivos: analisar a forma da administração em enfermagem desenvolvida na Santa Casa de Belo Horizonte-MG, tendo em vista a reestruturação administrativa iniciada em 1996; descrever como a equipe de enfermagem está percebendo a comunicação, a tomada de decisão e as relações interpessoais que ocorrem na unidade de internação; identificar possíveis tendências e perspectivas presentes na prática administrativa da enfermagem. 
REVELANDO A TRAJETÓRIA PERCORRIDA

Esta pesquisa foi desenvolvida dentro da abordagem do estudo de caso. Nos estudos de caso histórico-organizacionais o interesse do pesquisador recai sobre a vida de uma instituição e, este deve partir do conhecimento que tem sobre a organização ${ }^{(5)}$.

Delimitamos como campo de pesquisa a Unidade de Negócio II* composta por unidades de internação de pacientes adultos e provenientes do SUS. Estas unidades possuíam, no seu quadro de pessoal, enfermeiros e auxiliares de enfermagem com tempo de serviço na instituição superior a cinco anos, considerada a exigência de experiências anterior e posterior à reestruturação administrativa ocorrida em 1996.

O projeto de pesquisa recebeu a aprovação do Comitê de Ética e, na seqüência, foi realizada uma reunião com a Gerente de Enfermagem, para definição da operacionalização da coleta de dados. Utilizamos para a coleta de dados a entrevista semi-estruturada e para isso elaboramos um roteiro com perguntas relativas aos dados de identificação dos sujeitos e duas questões orientadoras, referentes ao estilo de administração em enfermagem desenvolvido na Santa Casa. As entrevistas foram individuais e agendadas previamente, realizadas após a assinatura do Termo de Consentimento PósInformação, no período de setembro a novembro de 1999.

Os sujeitos do estudo foram: três enfermeiras, seis auxiliares de enfermagem, a Gerente de Enfermagem e a Gerente Assistencial da Unidade de Negócio II, totalizando 11 entrevistas.

Os dados obtidos foram organizados segundo conteúdos temáticos. Procuramos, nessa etapa, agrupar as falas convergentes e divergentes, as quais originaram os eixos temáticos e sub-temas. As entrevistas foram codificadas em E1, E2, E3, (...) para serem apresentadas no texto, a fim de manter 0 sigilo e 0 anonimato das respostas.

\section{COMPREENDENDO A FALA DOS ENTREVISTADOS}

A organização dos dados coletados permitiu identificar dois eixos temáticos e respectivos sub-temas, que foram descritos e sustentados pelas falas dos sujeitos entrevistados.

$(R e)$ visitando um estilo "arcaico" de administração em enfermagem

Os discursos possibilitaram a compreensão das características e limitações do estilo de administração em enfermagem adotado anteriormente na Santa Casa, emergindo um sub-tema que veio confirmar os questionamentos elaborados durante nossa trajetória profissional como enfermeira na instituição em estudo.

Características e limitações de um estilo "arcaico" de administração em enfermagem

As respostas das entrevistadas mostram que antes da reestruturação administrativa ocorrida em 1996, o Serviço de Enfermagem da Santa Casa desenvolvia um sistema de gestão tradicional, evidenciando uma distância significativa entre a direção e o nível operacional. Esta situação impedia a aproximação entre as chefias e os seus subordinados, estabelecendo uma relação hierárquica rígida e impessoal. (...) Existia o Departamento de Enfermagem que também criava toda uma performance de distância (...) tínhamos aqui uma administração menos participativa, era mais distante dos colaboradores, aliás, o termo colaborador, ele advém dessa nova estrutura (...) éramos vistos muito como empregados somente. (E 1).

O estilo de gerência em enfermagem pautado nos moldes da administração tradicional "tem conduzido o conjunto de trabalhadores da enfermagem a experimentar uma solidariedade mecânica resultante da forte pressão social dos poderes instituídos hierarquicamente, inibindo a pluralidade de idéias, as diferenciações e as complementaridades profissionais" ${ }^{\prime \prime(6)}$.

Neste sentido, podemos dizer que as estruturas verticalizadas e centralizadas adotadas pelos Serviços de Enfermagem, de modo geral, têm favorecido a impessoalidade das relações hierárquicas, que vem impedindo ao longo dos anos 0 fortalecimento do trabalho em equipe, refletindo uma assistência descontínua, fragmentada e sem vínculos com os clientes.

Evidenciamos através dos relatos que antes da reestruturação administrativa as decisões relacionadas aos problemas de enfermagem ocorridos na unidade de internação estavam centralizadas na chefe do Departamento de Enfermagem. Assim, verificamos que as enfermeiras assistenciais não tinham autonomia, pois as decisões que tomavam não eram garantidas em virtude da centralização e verticalização desse poder. (...) antes no Departamento tinha a Irmã e mais aquele monte de gente para resolver as coisas dos andares (...). A Irmã (...) tinha que decidir para o hospital inteiro. (E 8)

O fato de a maioria das decisões ser tomada por uma pessoa, ou por um grupo restrito de pessoas localizadas no Departamento de Enfermagem, tornava o processo decisório lento e afastado da realidade dos setores. (...) eu achei que o sistema era arcaico, porque a gente passava diversas problemáticas com relação à equipe que a

\footnotetext{
* Unidade de Negócio foi a nomenclatura utilizada para denominar as unidades assistenciais (unidades de internação, centro cirúrgico, ambulatórios, entre outras) após a elaboração do novo organograma da Santa Casa com a implantação do SIGESC
} 
gente tinha (...) e demorava-se um longo tempo para resolver essas questões (...). (E 3)

A centralização das decisões é uma das características do modelo clássico de gestão, tendo como um dos princípios básicos a unidade de comando ${ }^{(7)}$. Este princípio concentra o poder decisório tornando as estruturas organizacionais rígidas e verticalizadas, fazendo com que os dirigentes, localizados no topo da pirâmide organizacional, raramente tenham contato com os reais problemas ocorridos nos setores de trabalho.

Apreendemos nos discursos que a comunicação também interferia de forma significativa na resolução dos problemas encontrados na unidade de internação, reforçando a sua morosidade, pois as informações eram repassadas por diversas chefias, apresentando um fluxo de comunicação truncado e ineficiente. Observamos que a maioria das informações não retornava ou demorava chegar aos setores de trabalho, deixando os enfermeiros nas unidades alheios ao processo decisório. (...) a gente fazia um comunicado (...) e entregava no Departamento de Enfermagem e ai entregava no Departamento de Pessoal, nós enfermeiros de ala não tínhamos o retorno daquilo ali (...) se era advertência, se era suspensão, às vezes a gente nem ficava sabendo, achava que o funcionário estava faltando e ele estava suspenso (...) e o Departamento de Enfermagem também não estava ciente (...). (E 6)

Os fundamentos da Teoria Clássica não priorizam a comunicação, pois estão voltados basicamente para a produção, eficiência e estrutura organizacional. Entretanto, mostram que há um pressuposto claro neste estilo de gestão, que considera a comunicação essencialmente escrita e descendente, ou seja, de cima para baixo ${ }^{(8)}$.

Neste sentido, a comunicação nos estilos clássicos de gestão é um importante fator de análise, pois tem sido freqüentemente monopolizada pelos indivíduos que ocupam cargos de chefia, na maioria das organizações, dificultando as iniciativas que propiciam o compartilhamento de idéias e informações ${ }^{(6)}$.

Visitando um estilo "contemporâneo" de administração em enfermagem

Este eixo temático sinaliza convergências e divergências que apareceram nos depoimentos das entrevistadas, relacionadas ao atual estilo de gestão desenvolvido pela enfermagem, após a implantação do SIGESC. Dos discursos emergiu um sub-tema que possibilitou compreender as características e limitações desse estilo de administração em enfermagem.
Características e limitações de um estilo "contemporâneo" de administração em enfermagem

Neste novo sistema de gestão da Santa Casa, as entrevistadas mencionam que agora a enfermeira assistencial está mais perto da equipe, tornando-se um ponto de referência para os auxiliares e os demais profissionais, evidenciando um relacionamento estreito entre as chefias e seus colaboradores, na tentativa de reduzir a rígida hierarquia presente no modelo de gestão adotado anteriormente. As idéias expressas foram identificadas na seguinte fala: A equipe encontrou mais um ponto de referência na supervisão*, mais confiança, porque a supervisão está mais presente. Ela está presente o tempo todo para resolver os problemas que ocorrem, ela é atuante (...). (E2)

Os depoimentos evidenciam ainda que as enfermeiras assistenciais, estando mais próximas da sua equipe, buscam cada vez mais conhecer o seu funcionário, dando a ele abertura para compartilhar seus problemas, até mesmo os de cunho pessoal. (...) hoje ficou muito mais fácil, porque você vivência mais de perto os problemas do setor e acompanha mais de perto cada funcionário (...) conhecendo cada um. Você é capaz de conhecer um pouco da característica de cada um, saber se a equipe é boa (...). (E 2)

Destacamos os discursos de algumas auxiliares de enfermagem que dizem respeito ao distanciamento que a gerente assistencial fica, do trabalho desenvolvido na unidade de internação. Notamos que estas entrevistadas conhecem a gerente e identificam o seu papel como responsável pela unidade. Contudo, afirmam não terem contato com essa profissional, uma vez que, na opinião delas, a mesma não participa do cotidiano da unidade, priorizando as relações formais, em detrimento das informais. Ela (a gerente) é distante, ela (...) não participa, pelo menos com a gente, ela não participa (...) é ausente mesmo. (E 10)

Atualmente, uma das tendências da administração contemporânea é tornar as relações interpessoais cada vez mais próximas reduzindo, significativamente, a distância entre as chefias centrais e a base da estrutura organizacional, ampliando as relações de poder, indo além das relações verticais ${ }^{(9)}$.

Os dados mostram que após a implantação do SIGESC, as relações interpessoais estabelecidas na unidade de internação, vem valorizando o trabalho em equipe. As entrevistadas reconhecem que 0 trabalho baseado em equipe é uma estratégia que permite a troca de experiência entre os profissionais dos diferentes turnos, pela a oportunidade de discutirem os problemas do setor conjuntamente. (...) um respeitando o trabalho do outro, trabalhando em equipe, discutindo os problemas, mas trabalhando em equipe, gerência, enfermeiro e auxiliar de enfermagem, trabalhando juntos (...). (E 6)

* Esclarecemos que na Santa Casa de Belo Horizonte-MG, o enfermeiro assistencial é habitualmente chamado de supervisor de enfermagem 
Como alternativa ao modelo de gerência clássica, a administração participativa "constitui uma forma de administração onde as pessoas tenham reais possibilidades de participar, com liberdade de discutir, sugerir, modificar, alterar, questionar uma decisão, um projeto ou uma simples proposta"(10).

Nesta perspectiva, entendemos que estilos de gerência contemporâneos, a exemplo do SIGESC, estão fortalecendo as bases da organização do trabalho na formação de equipes, que certamente tem sido a forma mais democrática, produtiva e humanizada de se efetuar o trabalho em saúde.

Segundo as entrevistadas existe uma aproximação de todos os profissionais que atuam nas unidades, buscando constituir um trabalho multidisciplinar, em que o gerente faz o papel de coordenador dessa equipe. (...) as AGMs (Avaliações Gerenciais Mensais) elas não são destinadas só a enfermagem, é um momento que senta todos da equipe, seja médicos, enfermeiros, funcionários (...) se der errado, não vai dar errado porque o outro não fez, e sim porque nós não fizemos o melhor. Então o eu (...) praticamente está descartado. (E 1)

Encontramos na literatura a proposta de gestão colegiada como alternativa à administração clássica. Esta enfatiza a importância da formação de equipes multidisciplinares, em que "todos os profissionais estariam envolvidos com um mesmo tipo de trabalho (...)". A base desse modelo gerencial é a constituição de "unidades de produção", com a presença de equipes profissionais autônomas, que estejam comprometidas e responsáveis com a saúde da população e, ao mesmo tempo consigam atingir certo grau de satisfação no trabalho ${ }^{(10)}$.

De modo geral, as entrevistadas apontam que atualmente a reunião é uma estratégia que está sendo muito utilizada pelas chefias (gerente e enfermeiras assistenciais) para a comunicação na unidade de internação. Este instrumento gerencial objetiva, em primeira instância, informar acerca dos resultados obtidos na unidade de internação, ressaltando as receitas e as despesas produzidas, mensalmente, em cada ala. Além disso, percebemos que nesse momento, tanto a gerente quanto a enfermeira assistencial têm oportunidade de discutir com a equipe, de forma participativa, os problemas dos setores, bem como planejar, conjuntamente, as metas a serem atingidas durante o mês. (...) ela (enfermeira) faz reunião com a gente (...) ela procura dar oportunidade de falar o que a gente está sentindo, (...) ela dá toda liberdade de falar (...). (E 5)

Verificamos que para a maioria das auxiliares de enfermagem, em alguns momentos a comunicação ainda ocorre de forma descendente na unidade de internação, contradizendo algumas falas descritas até então. Para estas profissionais, a comunicação geralmente assume um caráter autoritário que não proporciona um diálogo entre as chefias e os trabalhadores. Relatam que recebem as informações, em forma de ordens prontas, tendo poucas chances para se posicionarem em relação aos assuntos referentes ao setor que atuam. Para elas, a comunicação segue uma escala hierárquica vertical, em que a gerente detém grande parte das informações, que chega até os trabalhadores através da enfermeira assistencial. (...) as coisas vão primeiro na (gerente), depois que é passado para nós. A gente fica assim, como se fosse o último. (...) ela (enfermeira) faz reuniões, ela, conversa com a gente, passa o que está sendo passado para ela, é dessa forma que a gente fica sabendo (...). (E 10)

A reunião tem sido um instrumento adequado para discutir, coletivamente, as questões relativas ao processo de trabalho em saúde, o que proporciona um diálogo efetivo entre os diferentes profissionais da equipe multidisciplinar ${ }^{(11)}$.

Constatamos nas falas, após a implantação do SIGESC, que o processo decisório vem acontecendo de forma descentralizada na unidade de internação, pois os discursos apreendidos deixam nítida a autonomia da gerente e da enfermeira assistencial para resolverem grande parte dos problemas ocorridos no setor. Estes são resolvidos, em primeira instância, no próprio setor de trabalho, sendo encaminhados à gerente ou à outro nível hierárquico, somente em último caso. (...) porque o problema está lá no setor, vamos tentar resolver lá primeiro. Se for um problema que a gente das unidades não tem condição de resolver, passa para ela (gerente) (...). (E 6)

Para alguns entrevistados, as decisões estão acontecendo de forma mais ágil, uma vez que houve uma redução da cadeia hierárquica, aproximando mais as chefias dos locais de trabalho. Assim, tanto a enfermeira assistencial quanto a gerente tentam solucionar os problemas de imediato. (...) agora é mais rápido (...) se pode resolver um problema sim, se não pode às vezes quase nos mesmos dias a gente fica sabendo: "pode, ou não pode" (...). (E 8)

A literatura descreve a importância da descentralização administrativa dos Serviços de Enfermagem, uma vez que as decisões ficam o mais perto possível do local onde as ações são produzidas, permitindo assim, que os trabalhadores tenham autonomia e respaldo necessários para desenvolver 0 trabalho de forma mais criativa $\mathrm{e}$ responsável $^{(12)}$.

A maioria dos discursos emitidos por enfermeiras revela que na unidade de internação o processo decisório é feito de forma compartilhada. (...) nós estamos sempre abertas para resolver os problemas junto com os funcionários, seja problema de dentro da instituição, problema de dentro do setor (...) ou até um problema particular (...) e que ele esteja trazendo para dentro do ambiente de trabalho (...). (E 2)

Algumas falas identificam as divergências relacionadas ao processo decisório que ocorre na unidade de internação, revelando que ainda existe um certo autoritarismo nas decisões tomadas, principalmente, pela gerente assistencial, pois não leva em 
consideração as necessidades do setor, nem consulta a equipe para decidir sobre determinados assuntos. Sendo assim, as ordens já vêm prontas, somente para serem cumpridas pelos trabalhadores. (...) a pessoa muda de ala (...) ela não tem aquele gosto de trabalhar, começa a trabalhar de má vontade, começa a faltar muito, porque? Não tem aquela comunicação com a gerente, a gerente não procura saber, tira ela de uma ala e joga para outra sem saber (...). (E 11)

A situação descrita mostra o monopólio do poder por parte do enfermeiro. Esse tipo de atitude é decorrente do medo que as chefias têm de abrir espaços para o diálogo livre e transparente que criam a possibilidade de circular idéias diferentes e praticar a tomada de decisão compartilhada, o que provavelmente ameaçaria o poder instituído ${ }^{(1)}$. Sendo assim, gostaríamos de demarcar essa questão da centralização do poder que é muito presente nas relações da enfermagem e que pode influenciar, de maneira significativa, 0 desenvolvimento do trabalho cotidiano.

\section{TECENDO AS CONSIDERAÇÕES FINAIS}

Com a implantação do SIGESC, o estilo de administração em enfermagem desenvolvido atualmente na Santa Casa, está subsidiado em concepções gerenciais contemporâneas. As relações interpessoais são mais valorizadas, tentando diminuir os níveis hierárquicos e aproximar as chefias dos seus colaboradores. Além disso, estratégias como reuniões estão sendo utilizadas para estimular a abertura do diálogo, propiciando a troca de informações de forma democrática. Isso tem gerado decisões compartilhadas e mais

\section{REFERÊNCIAS BIBLIOGRÁFICAS}

1. Ferraz CA. transfiguração da administração em enfermagem: da gerência científica à gerência sensível. [dissertação]. Ribeirão Preto (SP): Escola de Enfermagem de Ribeirão Preto/USP; 1995.

2. Motta PR. Gestão contemporânea: a ciência e a arte de ser dirigente. 3.ed. Rio de Janeiro (RJ): Record; 1993.

3. Motta PR. Transformação organizacional: a teoria e a arte de inovar. Rio de Janeiro (RJ): Qualitymark; 1998.

4. Brito MJM. O enfermeiro na função gerencial: desafios e perspectivas na sociedade contemporânea. [dissertação]. Belo Horizonte (MG): Escola de Enfermagem/UFMG; 1998.

5. Triviños ANS. Introdução à pesquisa em ciência sociais: a pesquisa qualitativa em educação. São Paulo (SP): Atlas; 1992.

6. Ferraz CA. Gerenciamento de enfermagem: do modelo burocrático à administração flexível. Anais Encontro Nacional de Gerenciamento em Enfermagem; São Paulo (SP); 1997. próximas dos reais problemas encontrados nas unidades de internação, favorecendo a agilidade do processo de trabalho. Outro ponto que gostaríamos de destacar é a valorização do trabalho em equipe que enfatiza a cooperação e, além disso, incorpora a participação de outros profissionais da saúde, fortalecendo o trabalho multiprofissional.

Através das entrevistas percebemos que a realidade empírica não é homogênea, mas sim constituída por vários movimentos contraditórios, pois ora os sujeitos a representam de uma forma, ora de outra, evidenciando assim, os paradoxos presentes no cotidiano hospitalar.

Assim, entendemos que a enfermagem da instituição em estudo está vivendo um momento de transição, de rompimento de paradigmas, tentando superar os pressupostos da gerência clássica. Entretanto, algumas representações mostram que a administração em enfermagem na Santa Casa ainda apresenta traços do estilo "arcaico" de gerência, retratando certa impessoalidade nas relações interpessoais apresentando, em certos momentos, um processo decisório autoritário e a comunicação essencialmente descendente, em forma de ordens a serem cumpridas.

Acreditamos que a incorporação de novas posturas, novas atitudes e novos comportamentos acontecerá de forma gradativa na enfermagem, pois as características da gestão clássica são historicamente construídas e marcantes nessa profissão. Contudo, o novo estilo de gerência em enfermagem adotado na Santa Casa, a partir de 1996, mostra tendências e perspectivas que poderão ser adotadas em outras instituições hospitalares, contribuindo para a reorganização do processo de trabalho da enfermagem.

7. Motta FCP. Teoria geral da administração: uma introdução. 19.ed. São Paulo (SP): Pioneira; 1995.

8. Littlejohn SW. Fundamentos teóricos da comunicação humana. Rio de Janeiro (RJ): Guanabara; 1978.

9. Chiavenato I. Gerenciando pessoas: o passo decisivo para a administração participativa. 3. ed. São Paulo (SP): Makron Books; 1994.

10. Campos GWS. 0 anti-Taylor: sobre a invenção de um método para co-governar instituições de saúde produzindo liberdade e compromisso. Cad Saúde Pública 1998 out/dez; 14 (4):1-13.

11. Lima MAD. $O$ trabalho de enfermagem na produção de cuidados de saúde no modelo clínico. [dissertação]. Ribeirão Preto (SP): Escola de Enfermagem de Ribeirão Preto/USP; 1998.

12. Barros SMPF. Gerenciamento em saúde: implicações, tendências e perspectivas para a enfermagem. Anais Congresso Brasileiro de Enfermagem. Recife (PE); 1993. 